\title{
Regularities and Characterization of Arsenic Adsorption by Sediment in the Presence of Coexisting lons
}

\author{
Song Gang-fu*, E. Zheng-yang*, Li Hai-hua*†, Hua Yong-peng**, Yan Shao-feng**, Li Gui-liang*** and \\ Zhang Zan-ping*** \\ *Faculty of Environmental \& Municipal Engineering, North China University of Water Resources and Electric Power, \\ Zhengzhou 450011, China \\ **Henan Academy of Environmental Protection Sciences, Zhengzhou 450046, China \\ ***No. 4 Institute of Geological \& Mineral Resources Survey of Henan, Zhengzhou 450046, China \\ $†$ Corresponding author: Li Hai-hua; lihaihua918@163.com
}

Nat. Env. \& Poll. Tech.

Website: www.neptjournal.com

Received: 15-07-2019 Accepted: 06-10-2019

Key Words:

Sediment; Arsenic;

Adsorption; Kinetics;

Surface characterization;

Coexisting ions

\begin{abstract}
To reveal the regularity of arsenic adsorption of sediment, this study explores the law of arsenic adsorption by sediment when $\mathrm{Fe}^{3+}$ and $\mathrm{Mn}^{2+}$ coexist. The experimental results fit the first-order kinetic model and the second-order kinetic model. The surface physicochemical properties of sediment particles were analysed by scanning electron microscopy (SEM), nitrogen adsorption-desorption isotherm and fractal dimension. Characterization of surface area and pore distribution were measured by the BET equation and BJH equation. The results illustrate that the adsorption of arsenic by sediment shows the phenomenon of rapid adsorption in the early stage, slow adsorption in the middle stage and finally adsorption equilibrium. In the presence of coexisting ions, the BET specific surface area was as high as $20.14 \mathrm{~m}^{2} / \mathrm{g}$, the pore volume as $0.047826 \mathrm{~cm}^{3} / \mathrm{g}$, the surface pore volume as $43.25 \mathrm{~cm}^{3}$, and the surface fractal dimension Ds as the largest.
\end{abstract}

\section{INTRODUCTION}

Arsenic, which is a kind of metalloid, is similar to the heavy metal because the toxicity of arsenic ions in aqueous solution is very high (Chwirka 2000, Li 2017). In particular, arsenic is classified as a type of pollutant because its toxicity to humans and its migration and transformation in the environment are similar to heavy metals (Bissen 2003, He \& Charlet 2013). As a natural adsorbent, sediment has a large specific surface area and effectively reduces the concentration of heavy metals in water by adsorption (Wang \& Hu 2006, Withers \& Jarvie 2008, He 2005, Wang et al. 2006). For example, Jia et al. (2010) found that fine particles of sediment with a large specific surface area have a strong adsorption capacity. Huang et al. (1995) showed that the larger the sediment particle size, the smaller the adsorption rate. Zhao et al. (2003) found that the sediment in the middle reaches of the Yellow River has a strong adsorption capacity for $\mathrm{Cu}^{2+}$.

In the natural environment, the adsorption of arsenic in sediment occurs through competition or complexation under the coexistence of multiple ions (Ma 2017, Ma et al. 2015, Ghurye et al. 2004, Bhowmick et al. 2014, Kleinert et al. 2011). Yellow River Water Resources Bulletin (China
Water Resources Bulletin 2009-2017) shows that in the cross-section of Huayuankou Zhengzhou, iron and manganese often exceeded from 2009 to 2017. Based on the high content of $\mathrm{Fe}^{3+}$ and $\mathrm{Mn}^{2+}$ in the Yellow River water source of Zhengzhou City, the sediment particles were taken as the research object to study the change of arsenic adsorption and surface characteristics of sediment in the presence of $\mathrm{Fe}^{3+}$ and $\mathrm{Mn}^{2+}$. The study result can provide a theoretical basis and technical support for arsenic treatment and prevention of high $\mathrm{Fe}^{3+}$ and $\mathrm{Mn}^{2+}$ water sources.

\section{MATERIALS AND METHODS}

\section{Experimental Materials}

The experimental material was sediment taken from shallow water near the bank of the Yellow River at Huayuankou Madu village. The dried sand was crushed by a Pulveriser for 2 to 3 minutes and sieved through 325 mesh sample sieves to obtain 0.0375 to $0.088 \mathrm{~mm}$ size sediment. The sand was soaked in deionized water, washed with $\mathrm{NH}_{2} \mathrm{OH} \cdot \mathrm{HCl}$ and $\mathrm{H}_{2} \mathrm{O}_{2}$ in turn, baked at $60^{\circ} \mathrm{C}$ for 24 hours and then cooled to room temperature in a desiccator. 


\section{Experimental Procedure}

Firstly, $0.6 \mathrm{~g}$ of clean sand, $30 \mathrm{~mL}$ of deionized water and $0.3 \mathrm{~mL}$ of arsenic standard solution at a concentration of $0.01 \mathrm{mg} / \mathrm{mL}$ were put into a conical flask. Then $0.15 \mathrm{~mL}$ of iron standard solution or manganese standard solution at a concentration of $0.1 \mathrm{mg} / \mathrm{mL}$ was added to make the solution with the sediment at a concentration of $20 \mathrm{~kg} / \mathrm{m}^{3}$, the initial arsenic at a concentration of $0.1 \mathrm{mg} / \mathrm{L}$, and the coexistence of ion at a concentration of $0.5 \mathrm{mg} / \mathrm{L}$. After being oscillated in the constant temperature oscillator (speed $120 \mathrm{r} / \mathrm{min}$, temperature $20^{\circ} \mathrm{C}$ ), the solution was allowed to stand, be filtered and dried. The sampling time points were 5, 10, 15, 30, 60, 90, 120, 180, 240, 360, 480, 600, 1440min.

\section{Determination Methods}

Atomic fluorescence spectrophotometer (Model 8220) was used to determine the concentration of arsenic(III). Arsenic(III) (GSB 04-1714-2004) was purchased from the market. Quantification of arsenic(III) was based upon the calibration curves of standard solutions of arsenic(III) ion. The equation of calibration curve was $\mathrm{y}=44.3678 \mathrm{x}-31.0218$, and the detection limit of arsenic(III) was $0.01 \mathrm{mg} \cdot \mathrm{L}^{-1}$. The correlation coefficients were approximately 0.9997.

\section{Adsorption Kinetic Model}

The first-order kinetic model: The first-order kinetic model is the kinetic equation of the relationship between the reaction rate and the concentration of the reactant in the system. It can be expressed as:

$$
\frac{d q}{d t}=k_{1}\left(q_{e}-q_{t}\right)
$$

The second-order kinetic model: The second-order kinetic model is used to describe the adsorption process of divalent metal ions, assuming the adsorption is proportional to the amount of adsorption site on the adsorbent. It can be expressed as

$$
\frac{d q_{t}}{d t}=k_{2}\left(q_{e}-q_{t}\right)^{2}
$$

\section{Characterization}

The microscopic morphology of sediment particles was observed by Japan JSM-7001F field emission scanning electron microscope. The pore structure of the sample was measured by Japan BELSORP-Mini II specific surface area and porosity analyser. Nitrogen was used as the adsorption medium at a temperature of $77 \mathrm{~K}$. The measured pore size of sediment particles ranged from 0 to $100 \mathrm{~nm}$. Samples were degassed at $300^{\circ} \mathrm{C}$ for 12 hours before testing. The total specific surface area of sediment particles was calculated by the BET method. The pore volume of sediment particles was calculated by the BET equation and BJH equation respectively.

\section{RESULTS AND DISCUSSION}

\section{Study on Arsenic Adsorption by Sediment}

Curve of arsenic adsorption by sediment: Adsorption of arsenic by sediment is a dynamic equilibrium process. According to the experimental procedure, in the presence of $\mathrm{Fe}^{3+}$ and $\mathrm{Mn}^{2+}$, the adsorption rate of arsenic by sediment and the adsorption amount of sediment per unit time changed with time and the changing law is shown in Fig. 1.

From Fig. 1, it can be seen that the sediment adsorption is characterized by rapid adsorption in the early stage, slow adsorption in the middle stage, and finally adsorption equilibrium. On the whole, the adsorption rate of arsenic by sediment and the adsorption capacity of sediment show the same trend. Taking the analysis of arsenic adsorption rate as an example, when there was no $\mathrm{Fe}^{3+}$ and $\mathrm{Mn}^{2+}$, at 5 to $10 \mathrm{~min}$, the arsenic adsorption rate curve was not obvi-
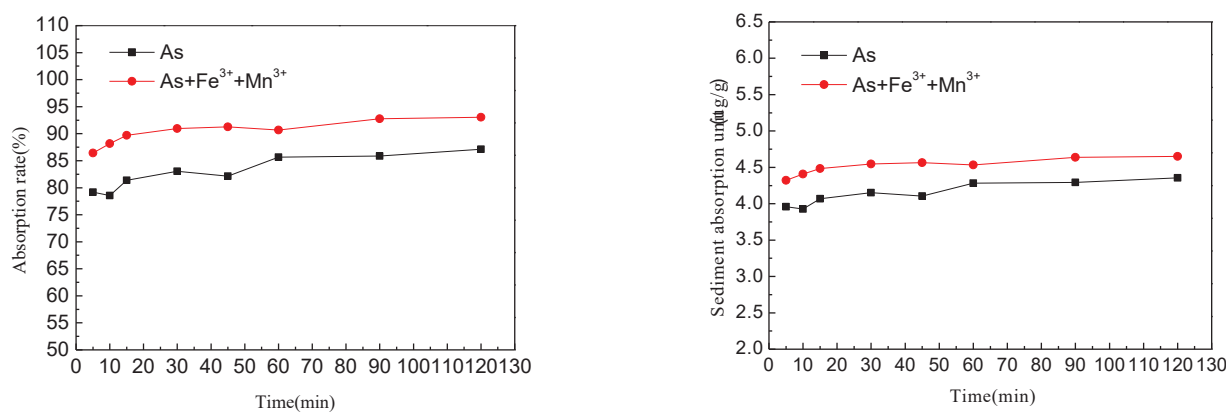

Fig. 1: Sediment adsorption curves. 
ous with time. The reason for this phenomenon is that the water-sand system is not well mixed. Just at the time when the adsorption reaction begins, the desorption also begins. The adsorption-resolution rate is inconsistent, which does not reach the dynamic stability, so the changes of arsenic adsorption rate are not stable. After adding $\mathrm{Fe}^{3+}, \mathrm{Mn}^{2+}$, the coexistence of two kinds of ions effectively counteracted the mutual interference, showing the phenomenon that the overall adsorption rate continuously increases. Subsequently, the arsenic adsorption rate increased significantly with the increase of time. After $60 \mathrm{~min}$, the arsenic adsorption rate changed little or no change over time, reaching the equilibrium of adsorption. Adsorption rate of arsenic by sediment ranged from $86.44 \%$ to $93.03 \%$ after adding $\mathrm{Fe}^{3+}$ and $\mathrm{Mn}^{2+}$. However, when there was only arsenic, the adsorption rate ranged from $79.137 \%$ to $87.109 \%$, indicating that the pres- ence of coexisting ions promotes the adsorption of arsenic by sediment.

Sediment arsenic adsorption kinetic model fitting: The first-order kinetics and the second-order kinetics were used to fit the data of arsenic adsorption by sediment. The fitting parameters are shown in Table 1 and the fitting model images are shown in Fig. 2.

Fig. 2 shows that the second-order kinetic equation can better describe the process of arsenic adsorption by sediment, which was a good linear correlation. From Table 1, it can be seen that the correlation coefficient $\mathrm{R}^{2}$ of the second-order kinetic model reached 0.996 to 0.998 . From the difference between the equilibrium adsorption quantity and the equilibrium adsorption quantity obtained from the experiment, the data of the second-order kinetics fitting differed by $0.02 \mu \mathrm{g} / \mathrm{g}$
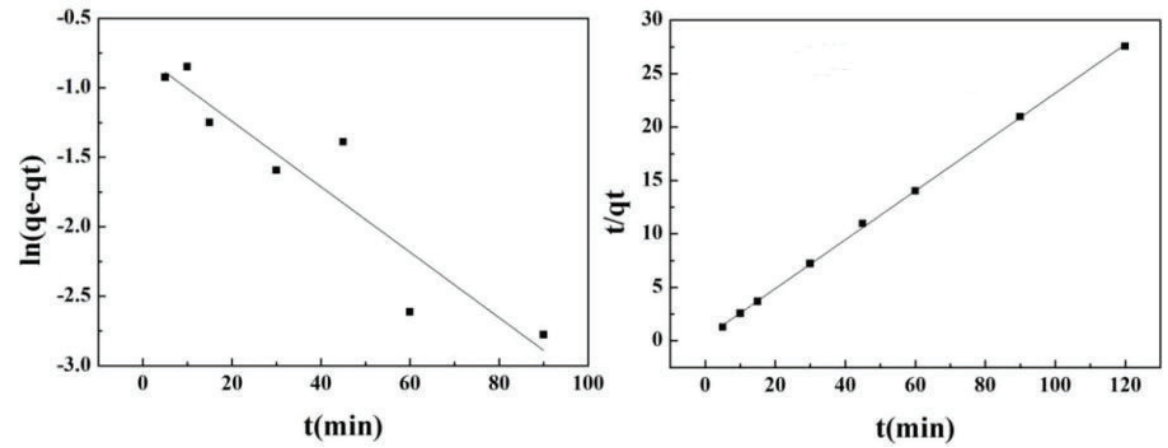

(a) Kinetic model fitting of arsenic adsorption by sediment alone
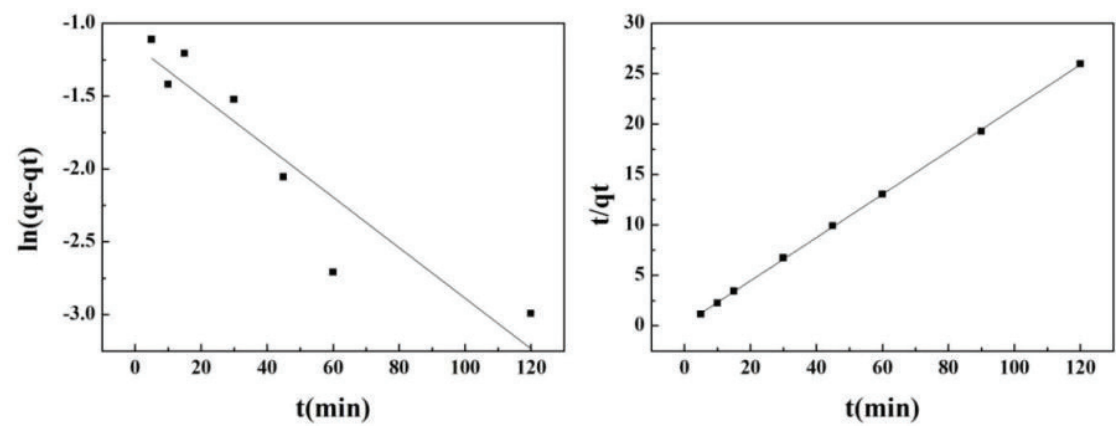

(b) Kinetic Model Fitting of Arsenic Adsorption by Sediment in the Presence of $\mathrm{Fe}^{3+}, \mathrm{Mn}^{2+}$

Fig. 2: The kinetic model fitting curves.

Table 1: The kinetic model parameters.

\begin{tabular}{|lllllllll}
\hline \multirow{2}{*}{ Conditions } & \multicolumn{3}{l}{ The first-order kinetics } & \multicolumn{3}{c|}{ The second-order kinetics } \\
\cline { 2 - 7 } & $\mathrm{k}_{1}$ & $\mathrm{q}_{\mathrm{e}}$ & $\mathrm{q}_{\mathrm{e}}{ }^{*}$ & $\mathrm{R}^{2}$ & $\mathrm{k}_{2}$ & $\mathrm{q}_{\mathrm{e}}$ & $\mathrm{q}_{\mathrm{e}}{ }^{*}$ & $\mathrm{R}^{2}$ \\
$\mathrm{As}$ & 0.0236 & 0.4628 & 4.3555 & 0.8506 & 0.1665 & 4.3760 & 4.3555 & 0.9996 \\
$\mathrm{As}+\mathrm{Mn}^{2+}+\mathrm{Fe}^{3+}$ & 0.0173 & 0.3156 & 4.6709 & 0.8460 & 0.2632 & 4.6666 & 4.6709 & 0.9998 \\
\hline
\end{tabular}


Table 2: Specific surface area, pore volume and average pore diameter of sediment particles.

\begin{tabular}{|llll|}
\hline Sample & BET specific surface area $/ \mathrm{m}^{2} / \mathrm{g}$ & BJH the total pore volume $/ \mathrm{cm}^{3} / \mathrm{g}$ & The average pore diameter/nm \\
\hline Clean sand & 11.52 & 0.043017 & 14.938 \\
Sand sample with As & 15.28 & 0.045787 & 13.074 \\
Sand sample with As $+\mathrm{Fe}^{3+}+\mathrm{Mn}^{2+}$ & 20.14 & 0.047826 & 11.295 \\
\hline
\end{tabular}

and $-0.0043 \mu \mathrm{g} / \mathrm{g}$ respectively, and the data of the first-order kinetic fitting varied greatly. This shows that under the laboratory conditions, the second-order kinetic equation is more suitable for describing the process of arsenic adsorption by sediment. The second-order kinetics assumes that the adsorption rate is governed by the chemical adsorption mechanism that involves electron-sharing or electron transfer between the adsorbent and the adsorbate. It indicates the presence of chemisorption in the process of arsenic adsorption by sediment, which is consistent with the chemical adsorption of $\mathrm{Cu}$ on sediment in the existing literature (Chen 2008). It indicates that arsenic has properties of heavy metals in the environment.

\section{Surface Characteristics of Sediment after Arsenic Adsorption}

Surface morphology changes of sediment samples before and after arsenic adsorption: As shown in Fig. 3, the appearance of the clean sand before and after the adsorption of arsenic significantly changed. When there was only arsenic, the surface porosity of sediment particles decreased due to the adsorption of arsenic, and the flow of water exerted different forces on the sediment so that the surface structure changed and became smoother. When $\mathrm{Fe}^{3+}$ and $\mathrm{Mn}^{2+}$ coexist, the three ions were adsorbed on the sediment surface, and migrated and transformed under the effect of water flow to form flaky and striped structures that adhered to the particle surface.
Adsorption isotherm of sediment sample: According to the difference of molecular adsorption in pores with different sizes, IUPAC (Arami-Niya et al. 2011, Yang et al. 2007) classifies adsorbed pores into three types: macropores with pore width $>50 \mathrm{~nm}$, mesopores with pore width from 2 to $50 \mathrm{~nm}$ and micropores with pore width $<2 \mathrm{~nm}$. Fig. 4 shows the adsorption-desorption isotherms of nitrogen on sediment particles.

As what can be seen from Fig. 4, the sediment adsorption isotherms belonged to the multi-layer adsorption model of porous media, and the pore structure was close to the slitshaped pores of the parallel walls. As for the volume of the unit mass of particles after nitrogen adsorption when the condition was near the saturated vapour pressure, cleaning sand was $37.45 \mathrm{~cm}^{3}$, the arsenic-containing solution was $39.87 \mathrm{~cm}^{3}$, and solution with $\mathrm{As}, \mathrm{Fe}^{3+}, \mathrm{Mn}^{2+}$ was $43.25 \mathrm{~cm}^{3}$. This shows that when the ions of $\mathrm{Fe}^{3+}, \mathrm{Mn}^{2+}$ are coexisting, the surface pore volume of the sediment sample after adsorption is the largest one. The specific surface area, pore volume and other pore structure parameters calculated by the BET and BJH equations are given in Table 2. It can be seen that BET and $\mathrm{BJH}$ in the sand sample containing $\mathrm{As}+\mathrm{Fe}^{3+}+\mathrm{Mn}^{2+}$ were larger than those in the sand sample only containing arsenic, indicating that the presence of $\mathrm{Fe}^{3+}, \mathrm{Mn}^{2+}$ has a greater impact on the pore structure of sediment particles.

Fractal dimension: According to the classical FHH model method, the fitted curve of the fractal dimension and the

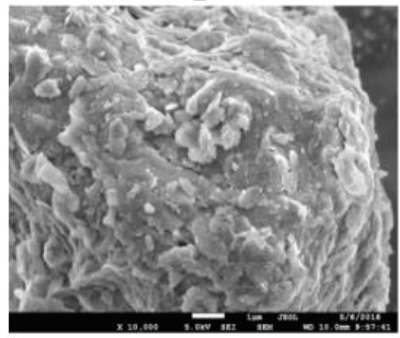

Particle a $(\times 10000)$

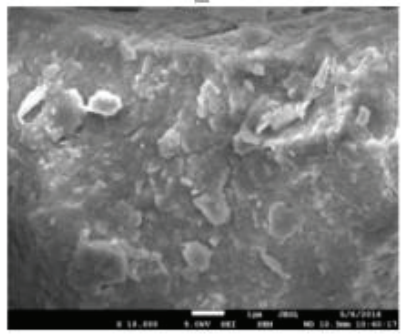

Particle b $(\times 10000)$

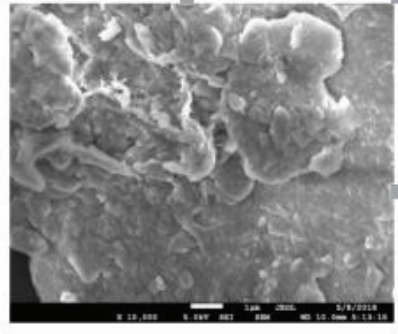

Particle c $(\times 10000)$

(a: clean sand; b: arsenic adsorption by sediment alone; c: arsenic adsorption by sediment in the presence of coexisting ions)

Fig. 3: SEM images of sediment particle surface under different states. 

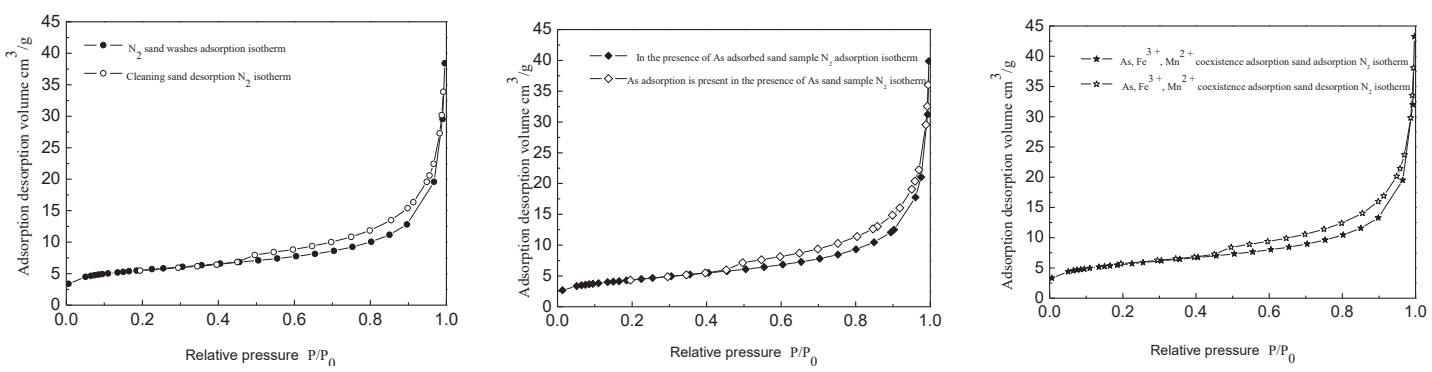

Fig 4: Adsorption-desorption isotherms.

surface fractal dimension of the clean sand sample and the adsorbed sample were calculated by the least square fitting method, as shown in Table 3 and Figs. 5 to 7.

The surface fractal dimension of sediment particles was between 2 to 3 , with the minimum number of clean sand and the maximum number of the sample with $\mathrm{As}, \mathrm{Fe}^{3+}$ and $\mathrm{Mn}^{2+}$. This is because the fractal dimension is the macroscopic displaying of the surface roughness and self-similarity of sediment particles and the slight change of microstructure does not change the fractal dimension of the surface, indicating that the presence of $\mathrm{Fe}^{3+}$ and $\mathrm{Mn}^{2+}$ has a significant effect on the microstructure of sediment particles.

\section{CONCLUSIONS}

This paper focuses on the analysis of the changes of arsenic adsorption and its surface characteristics of sediment in the presence of $\mathrm{Fe}^{3+}$ and $\mathrm{Mn}^{2+}$. The experimental results show that:

(1) The adsorption of arsenic by sediment is a dynamic equilibrium process, which shows the phenomenon of rapid adsorption in the early stage, slow adsorption in the middle stage, and finally adsorption equilibrium.

(2) Arsenic has properties of heavy metals in the environment. The adsorption of arsenic by sediment has the

Table 3: Surface fractal dimension of sediment particles $\left(R^{2}>0.98\right)$.

\begin{tabular}{|llll|}
\hline Sample & $\begin{array}{l}\text { FHH the equation of adsorption } \\
\mathrm{X}>0.35\end{array}$ & $\begin{array}{l}\text { FHH the equation of ad- } \\
\text { sorption } \\
0.7320<\mathrm{X}<0.9826\end{array}$ & $\begin{array}{l}\text { FHH the equation of } \\
\text { adsorption } \\
\mathrm{X}>0.35\end{array}$ \\
\hline Clean sand & 2.588 & 2.579 & 2.601 \\
Sand sample with As & 2.637 & 2.624 & 2.646 \\
Sand sample with As $+\mathrm{Fe}^{3+}+\mathrm{Mn}^{2+}$ & 2.672 & 2.659 & 2.674 \\
\hline
\end{tabular}

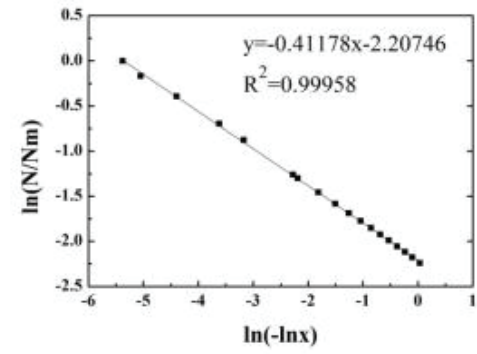

(a)

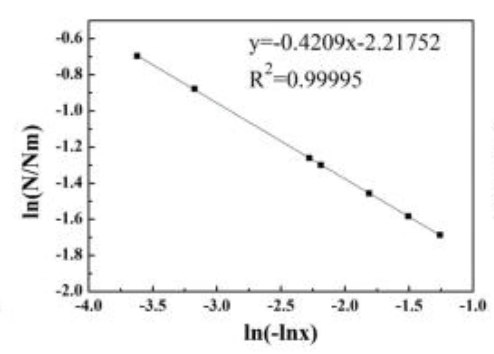

(b)

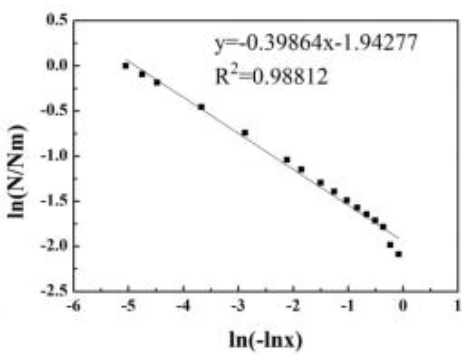

(c)

Fig. 5: Surface fractal dimension fitting curves of clean sand particles. 


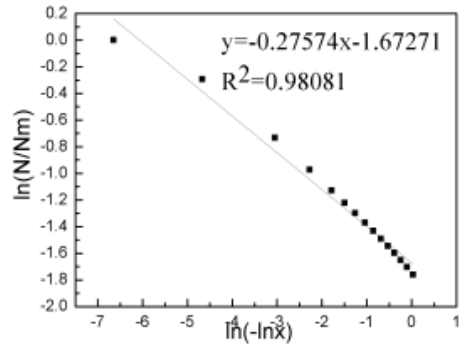

(a)

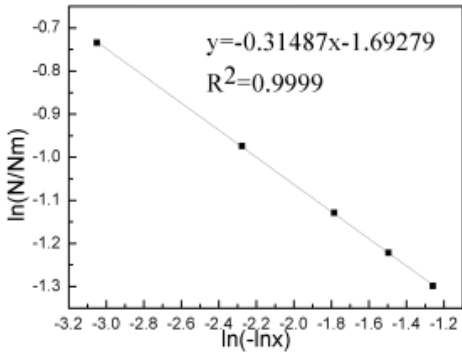

(b)

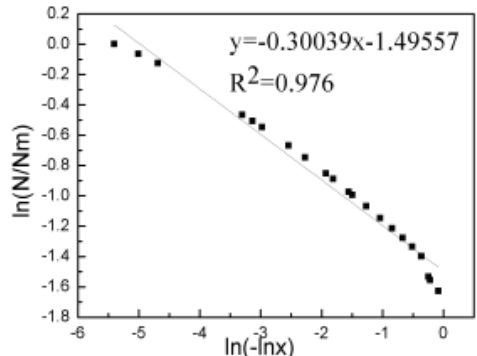

(c)

Fig. 6: Surface fractal dimension fitting curves of sediment particles after adsorption equilibrium with arsenic alone in lateral seepage.

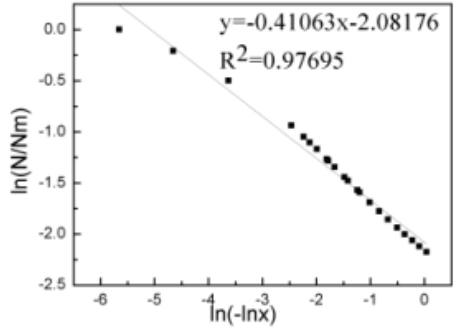

(a)

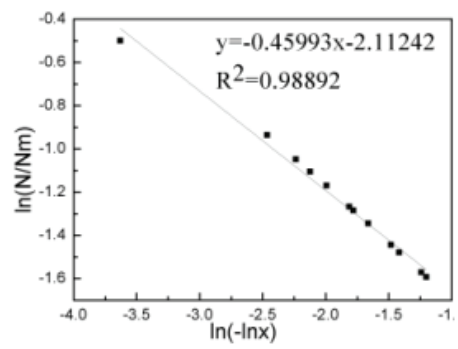

(b)

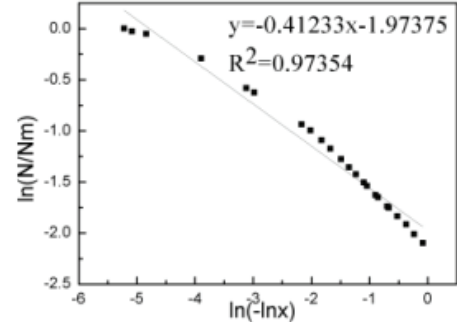

(c)

Fig. 7: Surface fractal dimension fitting curves of the sediment particles after adsorption equilibrium with the coexistent of arsenic, iron and manganese in lateral seepage.

(a) $\mathrm{x}>0.35$; (b) $0.7320<\mathrm{x}<0.9826$; (c) $\mathrm{x}>0.35$

function of chemisorption and the second-order kinetic equation is more suitable for describing the adsorption of arsenic.

(3) In the presence of coexisting ions, the BET specific surface area was as high as $20.14 \mathrm{~m}^{2} / \mathrm{g}$, the pore volume was $0.047826 \mathrm{~cm}^{3} / \mathrm{g}$, the surface pore volume of sand sample which was the largest was $43.25 \mathrm{~cm}^{3}$, and the surface fractal dimension Ds of arsenic adsorbed by sediment was the largest.

(4) The fractal dimension of sediment particles is the same as that of its specific surface area and pore volume. It can be used to characterize the surface roughness of sediment particles, i.e., micropore content.

\section{REFERENCES}

Arami-Niya, A., Daud, W. M. A. W. and Mjalli, F. S. 2011. Comparative study of the textural characteristics of oil palm shell activated carbon produced by chemical and physical activation for methane adsorption. Chemical Engineering Research and Design, 89(6): 657- 664.

Bhowmick, S., Chakraborty, S., Mondal, P., Van Renterghem, W., Van den Berghe, S., Roman-Ross, G., Chatterjee, D. and Iglesias, M. 2014.
Montmorillonite-supported nano-scale zero-valent iron for removal of arsenic from aqueous solution: kinetics and mechanism. Chem. Eng. J., 243: 14-23.

Bissen, M. and Frimmel, F. H. 2003. Arsenic-A review. Part I: occurrence, toxicity, speciation, mobility. Clean-Soil, Air, Water, 31(1): 9-18.

Chen, Z.H. 2008. Sediment Adsorption Heavy Metal Copper Ion Surface Morphology and Structural Characteristics. Tsinghua University.

Chwirka, J.D., Thomson, B.M. and Stomp, III J.M. 2000. Removing arsenic from groundwater. American Water Works Association Journal, 92(3): 79.

Ghurye, G., Clifford, D. and Tripp, A. 2004. Iron coagulation and direct microfiltration to remove arsenic from groundwater. J. Am. Water Works Assoc., 96(4): 143-152.

He, J. and Charlet, L. 2013. A review of arsenic presence in China drinking water. Journal of Hydrology, 492(10): 79-88.

He, Y. 2005. Water and Sediment Process and the Role of the Ecological Environment of the River. Wuhan University.

Huang, S.L., Wan, Z.H. and Wang, L.X. 1995. Static test on sediment desorption of heavy metal pollutants with different particle size. Research and Progress of Hydrodynamics (Series A), 2: 204-13.

Jia, X.F., Ying, Y.M., Li, Y. and Wang, L.C. 2010 Study on the interaction between sediment and heavy metal pollutants in the Yellow River. Yellow River, 8: 50.

Kleinert, S., Muehe, E.M., Posth, N.R., Dippon, U., Daus, B. and Kappler, A. 2011. Biogenic Fe(III) minerals lower the efficiency of iron-mineral-based commercial filter systems for arsenic removal. Environmental Science \& Technology, 45(17): 7533-7541. 
Li, H.H., Yan, W.F., Liang, Q., Zheng-yang, E. and Ge, K.J. 2017. Effect of initial arsenic concentration on sediment adsorption of arsenic. Nature Environment and Pollution Technology, 16(2): 627-632.

Ma, J., Guo, H.M. and Lei, M. 2017. Disparity of adsorbed arsenic species and fractions on the soil and soil colloids. Procedia Earth and Planetary Science, 17: 642-645.

Ma, J., Guo, H., Lei, M., Zhou, X., Li, F., Yu, T., Wei, R., Zhang, H., Zhang, $\mathrm{X}$. and $\mathrm{Wu}, \mathrm{Y} .2015$. Arsenic adsorption and its fractions on aquifer sediment: effect of $\mathrm{pH}$, arsenic species, and iron /manganese minerals. Water, Air \& Soil Pollution, 226(8): 260.

Ministry of water resources. China Water Resources Bulletin. Beijing: Ministry of water resources, 2009-2017.

Wang, G.Q. and Hu, C.H. 2006. Sediment Research Progress. China Water
Power Press, Beijing, pp. 392-413.

Wang, S., Jin, X., Bu, Q., Zhou, X. and Wu, F. 2006. Effects of particle size, organic matter and ionic strength on the phosphate sorption in different trophic lake sediments. Journal of Hazardous Materials, 128(2/3): 95-105.

Withers, P.J.A. and Jarvie, H.P. 2008. Delivery and cycling of phosphorus in rivers: are view. Science of the Total Environment, 400(1/2/3): 379-395.

Yang, H., Yan, R., Chen, H., Lee, D.H. and Zheng, C. 2007. Characteristics of hemicellulose, cellulose and lignin pyrolysis. Fuel, 86(12-13): 1781-1788.

Zhao, R., Ni, J.R., Sun, W.L. and Zhang L. 2003. Studies on the adsorption and desorption of copper ions by sediment in the middle Yellow River. Acta Scientiae Circumstantiae, 4: 441. 